\title{
Simulation in Physiotherapy Students for Clinical Decisions During Interaction with People with Low Back Pain. Randomized Controlled Trial
}

Carolina Sandoval-Cuellar ( $\square$ carolinasandoval@uniboyaca.edu.co)

Universidad de Boyaca Facultad de Ciencias de la Salud https://orcid.org/0000-0003-1576-4380

Martha Lucia Acosta-Otalora

Universidad de La Sabana

Angélica del Pilar Villarraga-Nieto

Universidad de La Sabana

Ruth Liliana Goyeneche-Ortegón

Universidad de Boyaca Facultad de Ciencias de la Salud

Adriana Lucia Castellanos-Garrido

Universidad de La Sabana

Rocio del Pilar Castellanos-Vega

Universidad de Boyaca Facultad de Ciencias de la Salud

Elisa Andrea Cobo-Mejía

Universidad de Boyaca Facultad de Ciencias de la Salud

Margareth Lorena Alfonso-Mora

Universidad de La Sabana

Research article

Keywords: simulation, physiotherapy, clinical skill, simulated patient

Posted Date: June 29th, 2020

DOI: https://doi.org/10.21203/rs.3.rs-32849/v1

License: (9) This work is licensed under a Creative Commons Attribution 4.0 International License.

Read Full License

Version of Record: A version of this preprint was published at BMC Medical Education on July 9th, 2021. See the published version at https://doi.org/10.1186/s12909-021-02812-7. 


\section{Abstract}

Background: Low back pain (LBP) is a symptomatology with a high global prevalence; health professionals, including physiotherapists, must have the skills to create professional interaction plans that permit a better quality of life for consultants. Clinical simulation can be a pedagogic setting that facilitates in students adequate training to acquire skills that improve professional reasoning in this clinical situation. The objective of this study was to compare the effects of clinical simulation with simulated patient (SP) versus simulation with role playing (RP) in physiotherapy students for decisionmaking in clinical skills while caring for a person with LBP.

Methods. Experimental study, with 42 participants from two Colombian universities, randomized into two groups ( $S P n=21, R P n=21)$. The clinical skill was evaluated during the interaction with a person with LBP for which the Objective Structured Clinical Examination (OSCE-ML) was validated for individuals with low back pain; thereafter, a pedagogical method was conducted that included clinical simulation and, finally, the OSCE-ML was applied again to compare both groups.

Results. Changes occurred in the OSCE-ML among both groups of students: the scores increased $(0.66$ and 0.59 in RP and SP, respectively), and neither of the two was superior (difference $0.0195 \% \mathrm{Cl}-0.21$ to $0.23)$.

Conclusion. Both types of simulation favour decision-making in professional reasoning in physiotherapy students during interaction with individuals with LBP.

Trial Registration: https://clinicaltrials.gov/ct2/show/NCT04428892 Identifying number: NCT04428892. Retrospectively registered.

\section{Background}

Low back pain (LBP) is one of the principal reasons for consulting health services globally $(1,2)$. Epidemiological reports state that the incidence of this symptomatology is between $60 \%$ and $90 \%$ in the Western population, affecting almost $80 \%$ of people at least once in their lives (3). LBP is considered one of the principal causes of absenteeism and the risks associated with it are diverse, including lifestyles, work and emotional factors, among others $(3,4)$. In physiotherapy, it is the most frequent reason for care, which is why professionals must recognize its nature and have the necessary skills to offer those people who consult them a comprehensive approach that minimizes reoccurrence and improves their quality of life. To achieve this, it is necessary for programmes in physiotherapy to provide sufficient tools to enable future professionals to have the skills to interact with people with LBP.

For this interaction, physiotherapists must: 1) perform physiotherapeutic examinations that include anamnesis, revision by systems, and the selection and application of tests and measurements; 2) discuss the examination findings, supported by professional reasoning; 3 ) formulate physiotherapeutic diagnosis and nrananncic in lino with tho findinac nhtained; 4) provide information to patients about a treatment Loading [MathJax]/jax/output/CommonHTML/jax.js 
plan according to the examination findings; 5 .) execute the treatment plan supported by scientific evidence; and 6) demonstrate humanized treatment and communication skills during the physiotherapeutic interaction.

Each of these abilities is related to clinical skills whose frame of action is based on decision-making regarding physiotherapeutic practice as a basis for the development of a professional profile based on acquiring diverse abilities and skills (5), such as professional reasoning supported by knowledge and values originating from high levels of quality focused on caring for patients (6). This is a process of application of integrated knowledge that includes intuition and permits timely development of examinations or physiotherapeutic interventions (6), through constant reflection during professional interaction.

Simulation can be used as a pedagogic tool that provides students with significant learning regarding decision-making in interacting with people, in this case patients with LBP. It is a potential strategy for developing diverse skills focused on the safety of the patient and the therapist. Moreover, it permits the inclusion of standardized patients (7); these are people who receive training in representing a specific health condition with a view to generating teaching or evaluation processes in interpersonal and/or clinical skills (8). Simulations with standardized patients give students an authentic learning experience (8) and, given their closeness to the real scenarios, facilitate effective identification of student performance.

Clinical simulation is supported by experiential learning. This focus allows students to get involved in direct interaction with what they are studying, rather than an intellectual observation or description, and enables them to make significant progress in their development through their own experience (9). The World Confederation for Physical Therapy (WCPT) states that students must be guaranteed opportunities for clinical interaction, which should always be accompanied by qualified professionals. Simulations may be linked to this process, given that controlled scenarios promote clinical reasoning, and theoretical information can be used to consolidate learning (10). This study used simulation with standardized patient generating a controlled scenario with a person manifesting LBP, seeking to use the knowledge acquired to make clinical decisions and respond to the needs of people with a health condition framed within a particular context. Thus, the aim of this study was to determine the effects of clinical simulation with standardized patients on physiotherapy students regarding decision-making on clinical skills while caring for a person with LBP.

\section{Methods}

\section{Design}

A randomized controlled trial was performed with formulation of equivalence with physiotherapy students from two Colombian universities. A registry was kept of the selection of participating students, elahorated hv a nrnfeccor rollahoratina with the study, for their subsequent randomization into two Loading [MathJax]/jax/output/CommonHTML/jax.js 
groups, SP and RP, to compare the effects of both types of pedagogic intervention supported by clinical simulation. The study was approved by the ethics committee at the University of Boyacá under record number 164 of 09 June 2016, and by the subcommission on research and ethics at University of La Sabana; it was considered of minimum risk and the students were assured that the research process would not affect their semester grades; hence, the evaluations were of a formative nature.

\section{Subjects}

The study included 42 fifth-semester students from two physiotherapy programmes in two Colombian universities, based on the formula for equivalency trials (11), in which $n=$ size per group; $Z_{1-\frac{\alpha}{2}}=$ normal two-tail standard deviation; $d=$ acceptable difference; $s=$ standardized standard deviation of both comparison groups.

$$
n=2 \frac{\left[\left(z_{1-\frac{\alpha}{2}}+Z_{\beta}\right)^{2}\right]}{d^{2}} s^{2}
$$

At the time of the study, the participants had taken a total of 87 credits and were actively enrolled in the participating programmes. The study excluded under-age subjects, those who had been internally or externally transferred from another academic programme in health, exchange students, and those repeating and with prior experiences in simulated practice in other assignments.

The study established a stratified sampling by blocks in each university by using the Epidat program version 3.1 and assigning participants to one of the SP and RP groups, a procedure overseen by a professor not involved with the study. A record of the process was kept (Fig. 1).

\section{Result measurements}

The study took into consideration the variables of sex, percentage of attendance of academic activities in SP and RP, level of bilingualism, score on the Colombian "SaberPro" state examination, and participants' accumulated academic grade point average for their undergraduate formation.

The Objective Structured Clinical Examination for low back pain (OSCE-LBP) was applied at the start and end of the period of the SP and RP interventions. This instrument was subjected to a content validity process with external experts in the study area (12). Application of the OSCE-LBP, as an evaluation process, was conducted by professors external to the research process to minimize evaluation bias. Training of the human resources applying the OSCE-LBP was carried out through systematic training in developing the OSCE-LBP in its different stages. Additionally, inter-rater correlation coefficient values were obtained (12), and the stages in which the professors had their best performance was identified compared with the denominated gold-standard evaluator (13).

The OSCE-LBP evaluates decision-making in clinical skills while caring for a person with LBP. It has Loading [MathJax]/jax/output/CommonHTML/jax.js ng to the skills or abilities described by the researchers 
regarding physiotherapeutic interaction for a person with LBP, thus:

1) Physiotherapeutic examination

1. Anamnesis: recognizes the symptoms or antecedents including red flags and personal aspects that can guide decision making by physiotherapists in relation to LBP.

2. Revision by systems: recognizes physical symptoms that indicate red flags or signs of peripheral nerve involvement, or signs of LBP.

3. Tests and measurements: applies tests and measurements related to mobility, articular integrity, strength of the lumbo-pelvic complex, and the integrity of the peripheral nerves of the lumbo-pelvic region.

2) Physiotherapeutic evaluation

1. Explains to a person with LBP whether their condition is related to nociceptive LBP, neuropathic LBP or another type (central sensitization).

3) Diagnosis, prognosis and intervention plan

1. Proposes reachable objectives according to the characteristics of the person's LBP.

2. Provides information to the patient about the treatment plan to follow according to findings obtained in the examination, bearing in mind that for mechanical LBP it is necessary to free the areas of the lumbo-pelvic region that have overloads, including muscles, ligaments and spinal disc units.

3. Is clear with the language used and in line with previous aspects of the interaction process.

4) Intervention

1. Includes therapeutic exercise according to the person's needs and capacity.

2. Includes manual techniques according to the needs.

3. Includes specific physiotherapy techniques according to the needs.

5) Demonstrates humanized treatment and communication skills during the process of professional interaction.

1. Verbal, proxemic, paralinguistic and assertive tactile communication is demonstrated according to the performance context.

The results obtained in the OSCE-LBP were established on a scale from 0.0 to 5.0 and equivalency success was determined in the SP and RP interventions obtaining a difference of 0.8 (14).

\section{Intervention}

For both groups, the same pedagogic process was established to achieve the skills related to the interaction with people with LBP (described using the OSCE-LBP) in the following manner: 
1. Learning guide process of therapeutic interaction with a person with LBP. The guide was distributed two weeks prior to conducting the SP or RP; its intention was to serve as a facilitator of the following phases of the learning process. The first part of the guide provided information and a series of independent activities for students to carry out a retrospective search about physiotherapeutic examinations for people with LBP. Some of the following parts were procedural and others aimed to seek scientific evidence related to the treatment of LBP.

2. Development of skills through laboratory workshops for the prescription and application of manual techniques and therapeutic exercise for the health condition studied. Each group had 10 hours of classroom sessions prior to the SP or RP, with each session seeking to develop the practical aspects of the learning guide, which in the manual techniques included therapeutic massage (caressing, effleurage, petrissage, friction) (15), and superficial techniques of myofascial release for paravertebral muscles and related to the lumbo-pelvic complex (16). The exercise techniques included central stabilization exercises (core) (17), analytic stretching and principles of postural reeducation (18).

3. Simulation activity: for group one with standardized patient, which for this study is denominated SP, and for group two RP.

The group denominated SP received a teaching strategy based on a class session with simulated practice for decision-making in clinical skills when caring for a person with LBP. Each session lasted approximately 120 minutes, and the clinical case used for the SP sessions was subjected to face validity with experts in the area of study.

Application of the simulated practice was conducted based on experiential knowledge, considering the following sequence of its elements:

- Context of the scenario: standardized for a clinical scenario of external consultation for the care of a person with LBP using physiotherapy.

- Patient standardization: based on the clinical case elaborated and validated, a script was created for the actor to interpret a person with LBP. Three simulated patients were trained per institution and their participation had a ratio of one patient for every eight students.

- Professor facilitator: a ratio was established of one professor for every eight students, and as in the case established, interpreted by the simulated patient, the professor started by approaching the person who was the object of care by following the characteristics of clinical reasoning.

- Guiding questions: the professor asked guiding questions that sought to stir reflection regarding the clinical situation observed, asking students to imagine other clinical situations and how the intervention would vary according to this.

- Concrete experience: students were permitted to interact with the simulated patient to carry out the reasoning process and thus provide care to the person.

- Debriefing: a meeting was held based on reflective conversation about the learning experience in 
mediated by dialogue and active listening; at the center of it were the students, who reflected on what they had done, and described their feelings and emotions, what was opportune, and what they would improve for subsequent opportunities with a person with LBP.

The RP group, in turn, received a class session based on a "role playing" simulation strategy, structured for the same purpose established in the SP group. This session lasted approximately 120 minutes, and the learning environment was the classroom in which students assumed different roles to act out; some of them acted as people with LBP and others as physiotherapists, and in several cases they developed an interaction process with a person with LBP.

\section{Statistical analysis}

Baseline: determined the distribution of the variables (extreme values, symmetries, kurtosis, types of distribution) - for qualitative variables, calculating relative frequencies (mode and erroneous data), and in all cases, evaluating the amount of data lost by each variable. The questionnaires were verified in the case of lost data. Description of the qualitative variables was conducted through absolute frequencies and percentage frequencies; the quantitative variables were described with a symmetric dispersion through medians and standard deviation. To compare the effect of the magnitude, an analysis by intention to treat was performed. Initially a difference of averages was estimated between the basal measurement and after the intervention; thereafter, a comparison was made of the interventions through a two-level hierarchical model of random intercepts and fixed coefficients (level 2: university; level 1: subject). The model is described by the following.

$$
y_{i j}=\beta_{o}+\beta_{1} I G_{1 i j}+\beta_{2} B M_{2 i j}+U_{o j}+e_{i j}
$$

i: Individual, j: University, IG: Intervention Group, MB: Basal Measurement

Estimation of parameters was used with a 95\% confidence level. Analyses were carried out using STATA version 14.

\section{Results}

The participating population was mostly of female sex, with a mean age of 21 years, an academic average of 3.6 (over 5), and an average of 87 credits taken in the Physiotherapy programme at each university (Table 1). 
Table 1. Characteristics of the participants

\begin{tabular}{|lll|}
\hline & $\begin{array}{l}\text { Role Playing (RP) } \\
\mathrm{n}=21\end{array}$ & $\begin{array}{l}\text { Simulated Practice } \\
(\mathrm{SP}) \mathrm{n}=21\end{array}$ \\
\hline Sex & $7(33.4 \%)$ & $3(14.3 \%)$ \\
\hline Male & $14(66.6 \%)$ & $18(85.7 \%)$ \\
\hline University & & \\
\hline University of La Sabana & $9(42.9 \%)$ & $12(57.1 \%)$ \\
\hline University of Boyacá & $12(57.1 \%)$ & $9(42.9 \%)$ \\
\hline & & \\
\hline Age & $21.4[2.1]$ & $21.6[2.3]$ \\
\hline Academic average & $3.7[0.3]$ & $3.6[0.2]$ \\
\hline Bilingualism & $7.8[4.2]$ & $8.9[4.8]$ \\
\hline Credits taken & $87.2[13.2]$ & $84.7[11.6]$ \\
\hline$x[s d]=$ average [standard deviation] & \\
\hline $\mathrm{n}(\%)=$ absolute frequency (percentage) & \\
\hline
\end{tabular}

The table 2 shows that in both RP and SP, the final score increases ( 0.66 and 0.59 in RP and SP, respectively); when comparing the interventions, it is noted that neither of the two was superior (difference $0.0195 \% \mathrm{Cl}-0.21$ to 0.23 ). The study reports $100 \%$ participant adherence.

Table 2. Comparing the interventions

\begin{tabular}{|c|c|c|c|c|c|c|c|c|c|c|}
\hline & \multicolumn{2}{|c|}{$\begin{array}{c}\text { Role Playing } \\
\mathrm{n}=21\end{array}$} & \multicolumn{2}{c|}{$\begin{array}{c}\text { Simulated Practice } \\
\mathrm{n}=21\end{array}$} & \multicolumn{2}{c|}{$\begin{array}{c}\text { Difference in Role } \\
\text { Playing }\end{array}$} & \multicolumn{2}{c|}{$\begin{array}{c}\text { Difference in Simulated } \\
\text { Practice }\end{array}$} & \multicolumn{2}{c|}{$\begin{array}{c}\text { Difference in both } \\
\text { interventions }\end{array}$} \\
\hline & $\begin{array}{c}\text { Baselin } \\
\mathrm{e} \\
\bar{x}[s]\end{array}$ & $\begin{array}{c}\text { Post- } \\
\text { intervention } \\
\bar{x}[s]\end{array}$ & $\begin{array}{c}\text { Baselin } \\
\mathrm{e} \bar{x}[s]\end{array}$ & $\begin{array}{c}\text { Post- } \\
\text { intervention } \\
\bar{x}[s]\end{array}$ & Diff. & $95 \% \mathrm{Cl}$ & Diff. & $95 \% \mathrm{Cl}$ & Diff. & $95 \% \mathrm{Cl}$ \\
\hline \multirow{3}{*}{ Score } & $\begin{array}{c}2.07 \\
{[0.45]}\end{array}$ & $2.73[0.51]$ & $\begin{array}{c}2.16 \\
{[0.42]}\end{array}$ & $2.76[0.48]$ & -0.66 & -0.97 to -0.34 & -0.59 & -0.89 to -0.30 & 0.01 & $\begin{array}{c}-0.21 \text { to } \\
0.23\end{array}$ \\
\hline
\end{tabular}

\section{Discussion}

The study results reveal that pedagogic strategies supported by simulation improve clinical skills in intorantinn with nonnlo with I RD Rnth tvnos of simulation generated positive changes in the: 1) Loading [MathJax]/jax/output/CommonHTML/jax.js 
examination; 2) evaluation; 3) diagnosis; 4) prognosis; and 5) physiotherapeutic intervention. To date, publications have not been found using simulation to train physiotherapists to interact with people diagnosed with LBP, which could be a powerful tool for enhancing decision-making with respect to one of the primary reasons for consulting health services, and high-quality physiotherapy could be a solution for reducing the reoccurrence of this symptomatology.

Other clinical areas in which physiotherapists work have already demonstrated the positive effects of simulation as a pedagogic approach that develops integrally the skills of the future professional. Some antecedents mention that simulation improves teamwork and the understanding of professional roles (19); it can replace part of the time in clinical institutions (14), contribute to education in cardiorespiratory physiotherapy (20), improve confidence in students and enhance the procedural skills in the different performance areas (21), among others.

For the specific case of performance skills in the musculoskeletal area, Wright et al., (2018) report that after a $100 \%$ immersion in clinical simulation for 18 days, students showed significant improvement in their confidence and, in general, in their performance in regard to the clinical approach to patients. The authors report that students who were exposed to rotations in simulated scenarios demonstrated a significantly higher performance in clinical skills than those who did not undergo this immersion.

The types of simulation used for this study were of high fidelity with standardized patients and role playing. According to the results, both types contributed to the integration of knowledge developed along the pedagogical route constructed to achieve the learning objectives related to the therapeutic interaction with a person with LBP. Respect to simulation with a simulated patient, the potential benefit is that direct interaction with others with a specific training can create an environment quite close to the reality, which can become an alternative with effects comparable with conventional clinical practices (22). With respect to role playing, the literature also reports that it leads students to appropriate the characteristics of the subjects implied in the process and this facilitates integration of knowledge (23).

Although research on clinical simulation as a pedagogic strategy in physiotherapy has increased, it is necessary to continue with reports of this type to enhance student training in therapeutic interaction and thus improve decision-making in the clinical reality (24).

\section{Conclusion}

From the results herein, it may be stated that simulation enhances decision-making in physiotherapy students during the process of professional reasoning regarding a person with LBP; as for the design proposed, equivalence is evidenced between both types of simulation, RP and SP.

\section{Abbreviations}

LBP: Low back pain; SP: Clinical simulation with simulated patient; RP: Simulation with role playing; 


\section{Declarations}

\section{Ethics approval and consent to Participate:}

this study was approved by the ethical committee of clinical center Universidad de Boyaca in June of 2016. The study included an informed consent signature in a writing way for all participants according to a Helsinki declaration and with 8430 Colombian law (1993).

\section{Consent for publication:}

Not Applicable

\section{Consent to publish:}

all authors have given their consent to publish this study

\section{Availability of data and materials:}

the data collected is available in the public archive of the physiotherapy program of the Universidad de Boyaca.

\section{Competing interests:}

the authors declare not have conflict of interest about this manuscript.

\section{Funding:}

This study was funded by the Universidad de La Sabana, Universidad de Boyaca and the Colombian Association of Physiotherapy Faculties (known as ASCOFAFI in Spanish). Universities mentioned above developed the role of design, data recollection, outcome analysis, and results divulgations included writing manuscript. ASCOFAFI founded the data recollections activities

\section{Authors Contributions:}

MLAM, CSC, ADPV, and RPCV were responsible for the design of the study. EACM, RLGO, and MLAO gave advice on assessment, viability, and intervention process respectively, all of them contribute to the research paper writing and have read and approved the manuscript. 


\section{Acknowledgements:}

The authors thank the students who participated as subjects of the experiment and professors who collaborated in the blind evaluation processes, as well as the University of La Sabana, the University of Boyacá that allowed the application in their facilities and the Colombian Association of Physiotherapy Faculties (known as ASCOFAFI in Spanish) as a funder of research processes.

\section{Contribution of paper:}

This is an RCT that explores the use of clinical simulation with simulated patient as a teaching method in decision making by physiotherapists versus traditional use of role playing

\section{References}

1. Hartvigsen J, Hancock MJ, Kongsted A, Louw Q, Ferreira ML, Genevay S, et al. What low back pain is and why we need to pay attention. Lancet. 2018;6736(18):1-12.

2. Maher C, Underwood M, Buchbinder R. Non-specific low back pain. Lancet. 2017 Feb;389(10070):736-47.

3. Delgado JÁG, Lara GV, Torres J del CM, Morales IP. Epidemiología del dolor de espalda bajo. Investig Medicoquirúrgicas. 2014;6(1):112-25.

4. Palomino Aguado B, Jiménez Cosmes L, Ferrero Méndez A. El dolor lumbar en el año 2009. Rehabilitacion. 2010;

5. ASCOFI, ASCOFAFI, COLFI A. Perfil profesional y Competencias del fisioterapeuta en Colombia. Bogotá, Colombia; 2015.

6. Atkinson HL, Nixon-Cave K. A tool for clinical reasoning and reflection using the international classification of functioning, disability and health (ICF) framework and patient management model. Phys Ther. 2011;91(3):416-30.

7. Phillips AC, Mackintosh SF, Bell A, Johnston KN. Developing physiotherapy student safety skills in readiness for clinical placement using standardised patients compared with peer-role play: A pilot non-randomised controlled trial. BMC Med Educ. 2017;

8. Ruiz-Moral R, Caballero-Martínez F. Programa para seleccionar y entrenar pacientes estandarizados en el contexto de un currículo universitario de simulación clínica. FEM Rev la Fund Educ Médica. 2015;

9. Ariza MR. El Aprendizaje Experiencial Y Las Nuevas Demandas Formativas. Rev Antropol Exp. 2010;8:89-102.

10. World Confederation for Physical Therapy. Policy statement: Education WCPT. 2017.

11. Zhong B. How to calculate sample size in randomized controlled trial? J Thorac Dis. 2009;1(1):51-4. 
12. Carvajal A, Centeno C, Watson R, Martínez M, Sanz Rubiales A. How is an instrument for measuring health to be validated?. An Sist Sanit Navar [Internet]. 2011;34:63-72. Available from: http://www.ncbi.nlm.nih.gov/pubmed/21532647

13. Campo-Arias A, Herazo E. Concordancia intra- e interevaluadores. Rev Colomb Psiquiat. 2010;39(2):424-32.

14. Blackstock FC, Watson KM, Morris NR, Jones A, Wright A, McMeeken JM, et al. Simulation Can Contribute a Part of Cardiorespiratory Physiotherapy Clinical Education. Simul Healthc J Soc Simul Healthc [Internet]. 2013;8(1):32-42. Available from: http://content.wkhealth.com/linkback/openurl? sid=WKPTLP:landingpage\&an=01266021-201302000-00007

15. Furlan AD, Imamura M, Dryden T, Irvin E. Massage for low back pain: An updated systematic review within the framework of the cochrane back review group. Spine (Phila Pa 1976). 2009;

16. Pilat A. Terapias Miofasciales: Induccion Miofascial. Mcgraw-Hill Interamericana De España S.L., editor. 2003.

17. Wang XQ, Zheng JJ, Yu ZW, Bi X, Lou SJ, Liu J, et al. A Meta-Analysis of Core Stability Exercise versus General Exercise for Chronic Low Back Pain. PLoS One. 2012;

18. Paolucci T, Attanasi C, Cecchini W, Marazzi A, Capobianco S V., Santilli V. Chronic low back pain and postural rehabilitation exercise: A literature review. Journal of Pain Research. 2019.

19. Dennis D, Furness A, Duggan R, Critchett S. An Interprofessional Simulation-Based Learning Activity for Nursing and Physiotherapy Students. Clin Simul Nurs. 2017;

20. Blackstock FC, Watson KM, Morris NR, Jones A, Wright A, McMeeken JM, et al. Simulation can contribute a part of cardiorespiratory physiotherapy clinical education: Two randomized trials. Simul Healthc. 2013;

21. Wright A, Moss P, Dennis DM, Harrold M, Levy S, Furness AL, et al. The influence of a full-time, immersive simulation-based clinical placement on physiotherapy student confidence during the transition to clinical practice. Adv Simul. 2018;

22. Pritchard SA, Blackstock FC, Nestel D, Keating JL. Simulated patients in physical therapy education: Systematic review and meta-analysis.(Research Report). Phys Ther. 2016;96(9):1342.

23. Brauer $S$ et al. Proceedings of the Australian and New Zealand Association for Health Professional Educators. In: mproving clinical preparation, communication, confideence and satisfaction in physiotherapy students through role-playing. Launceston; 2009. p. 84.

24. Judd BK, Scanlan JN, Alison JA, Waters D, Gordon CJ. The validity of a professional competence tool for physiotherapy students in simulation-based clinical education: A Rasch analysis. BMC Med Educ. 2016;

\section{Figures}




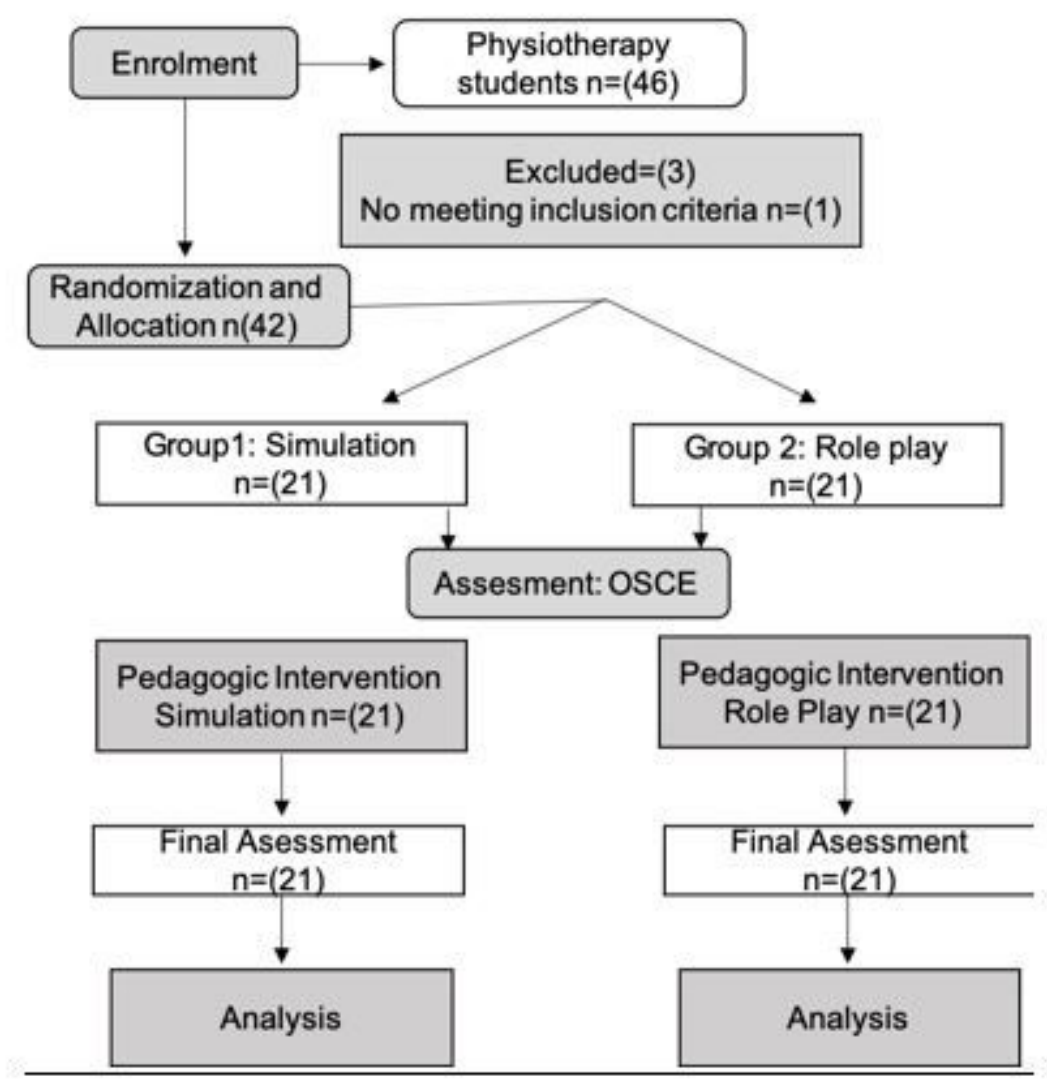

Figure 1

Flow diagram of the study "Simulated practice in physiotherapy students from the University of Boyacá and University of La Sabana on decision-making in clinical skills while caring for a person with LBP". Intervention group: Simulated practice; control group: "Role playing".

\section{Supplementary Files}

This is a list of supplementary files associated with this preprint. Click to download.

- CONSORT2010ChecklistMSWord.doc 